\title{
Impact of an enabling performance measurement system on task performance and job satisfaction
}

\author{
Guilherme Eduardo de Souza \\ Universidade Federal da Integração Latino-Americana, Foz do Iguaçu, PR, Brazil \\ Email: guilherme.souza@unila.edu.br
}

Ilse Maria Beuren

Universidade Federal de Santa Catarina, Programa de Pós-Graduação em Contabilidade, Florianópolis, SC, Brazil

Email: ilse.beuren@ufsc.br

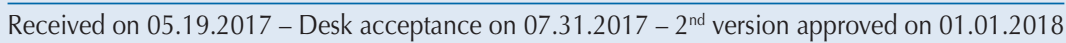

\begin{abstract}
This study analyzes the impact of a Performance Measurement System (PMS) with enabling characteristics, mediated by psychological empowerment, on task performance and job satisfaction in a Shared Services Center (SSC). The literature on management controls has sought to identify elements that are capable of improving performance, and the enabling controls associated with psychological empowerment may bring new clues to this discussion. Given the ability of the context to affect individuals' perceptions, it is important to understand the impacts of controls on satisfaction, which can lead to practices that are more aligned with their expectations and favorable results for the organization. The results of the study indicate that the characteristics of a PMS affect the motivation of individuals, so that implementing systems with enabling characteristics can contribute to employees' perceptions regarding their control over and autonomy in their work. In the mechanistic structure of the SSC, the way in which PMSs are shaped can avoid potential adverse results from less organic structures in employees' perceptions of psychological empowerment. A survey was conducted at a SSC located in southern Brazil, which provides administrative, financial, and accounting services. Eighty-eight of the 125 operational employees participated, corresponding to $70 \%$ of the total. The research tool used was based on the assertions of the studies conducted by Mahama and Cheng (2013), Spreitzer (1995), Tarrant and Sabo (2010), and Van Der Hauwaert and Bruggeman (2015). Structural Equation Modeling was used to test the hypotheses. Evidence drawn from the research indicates that the use of an enabling PMS can contribute to the balance needed in companies between levels of formal controls and psychological empowerment to obtain employee job satisfaction and task performance.
\end{abstract}

Keywords: Enabling PMS, task performance, job satisfaction, psychological empowerment, Shared Services Center.

Correspondence address:

Ilse Maria Beuren

Universidade Federal de Santa Catarina, Programa de Pós-Graduação em Contabilidade

Campus Universitário Reitor João David Ferreira Lima - CEP: 88040-900

Trindade - Florianópolis - SC - Brazil 


\section{INTRODUCTION}

Management control systems (MCSs), which are composed of management accounting, planning, budgeting, project management, information and reporting, and performance measurement systems (Simons, 1992), aim to influence the behavior and obtain the cooperation of groups of individuals or units towards an organization's objectives (Flamholtz, Das \& Tsui, 1985). According to Widener (2014), factors related to human behavior are the main explanation for the variance in the performance of organizations.

Within this context, performance measurement systems (PMSs) provide support tools that offer a broad overview of the main processes and the levels of achievement of an organization's objectives (Franco-Santos, Lucianetti \& Bourne, 2012). These systems enable the strategy for the whole firm to unfold, by communicating what are considered to be the main factors, such as customer service, sales, and production, moving up through the management levels and culminating in senior management (Demartini, 2014). In addition, studies that address elements of PMSs highlight that characteristics of the work, such as feedback (Liden, Wayne \& Sparrowe, 2000) and management practices that involve the sharing of information, responsibility, and accountability (Seibert, Silver \& Randolph, 2004), can affect individuals' job satisfaction. However, adapting this system to the needs of an organization and the individuals in it requires care with its design, implementation, use, and scope (Chenhall, 2003; Hall, 2008).

Due to their complexity, PMSs have been studied using various approaches, based on economic, sociological, or psychological theories or combinations of them, in an attempt to shed light of the mechanisms underlying these systems (Franco-Santos et al. 2012). The psychological approach enables PMSs to be understood from the individual's point of view (Birnberg, Luft \& Shields, 2006). This approach is relevant considering that company performance begins at the individual level (Mahama \& Cheng, 2013). In addition to this is the fact that a company's structure and processes can shape the actions of its staff. In this context, management accounting practices present in PMSs can influence individuals' mental representations by establishing goals, changing reference points, and altering beliefs. The introduction of demands leads to tensions, inconsistencies, and conflicts that can affect individuals' efforts, which can generate motivation, leading individuals towards the goals and objectives, or demotivation, resulting in dissatisfaction, a reduction in self-esteem and interpersonal trust, and a sense of lost control (Adler \& Borys, 1996; Birnberg et al., 2006).

PMSs cover informational elements, feedback, feedforward, and rewards (Demartini, 2014), which are susceptible to affecting psychological empowerment and favoring performance at the individual level of analysis, such as managerial (Hall, 2008; Marginson, Mcaulay, Roush \& Van Zijl, 2014) and task performance (Mahama \& Cheng, 2013). However, studies to identify the mechanisms by which characteristics of a PMS influence the perception of employees regarding their work environment, motivation, and consequently their behavior and attitudes, have generally investigated isolated characteristics of accounting practices, such as the providing of feedback, access to information, goal characteristics, and the visibility of processes (Birnberg et al., 2006; Franco-Santos et al., 2012; Liden et al., 2000; Seibert et al., 2004). Few studies have analyzed such aspects in combination, based on the PMS, such as Hall (2008), when addressing the comprehensibility of these systems, and Marginson et al. (2014), when analyzing the effects of using financial and non-financial measures.

The logic underlying psychological empowerment derives from the idea of individuals having a sense of control over their work environment (Spreitzer, 2008). Psychological empowerment can lead to positive results by giving employees more involvement, control, and autonomy in their activities, which occur via individuals' joint perception of meaning, impact, competence, and self-determination in their work environment (Spreitzer, 2008). Empowerment apparently signals a conflict with the idea of managerial control. Employees' need to be flexible in order to adapt to changes coexists in companies with their need to apply management controls in their processes to ensure the efficient use of resources and monitor results (Ahrens \& Chapman, 2004; Simons, 1992). If on one hand the perception in incentivizing greater autonomy in the work leads to favorable results, which range from improving motivation to raising the employees' and consequently the company's ability to respond (Spreitzer, 2008), on the other hand management controls are needed for efficient processes.

In this context, as a way of distinguishing between good and bad rules present in management processes, and consequently reflected in the management controls and in the different results arising from their application, Ahrens and Chapman (2004) used the Theory of Bureaucratic 
Formalization from Adler and Borys (1996) to suggest that formal control systems can have enabling or cohesive characteristics. Thus, organizational processes can be designed (i) in an enabling way, by granting employees more responsibility and autonomy, or (ii) in a coercive way, by designing rigid processes that are barely interactive. Such elements, when applied to management controls, suggest that enabling controls can favor greater employee integration with their work activities, while coercive controls work in the opposite direction (Ahrens \& Chapman, 2004). Coercive and enabling controls provide an alternative analysis for explaining the use of controls at different levels of a company, so that it can execute the strategy of reducing production costs and at the same time be more flexible (Ahrens \& Chapman, 2004).

However, to evaluate these relationships, it is necessary to pay attention to the context of the study, which in this case is a Shared Services Center (SSC). Kuntz and Roberts (2014) state that organizations have been relocating their support activities to foreign subsidiaries in order to obtain the benefits of economies of scale and favorable labor market conditions in other countries. One example of this are SSCs, which are structures that concentrate an organization's administrative support activities, reducing the duplicity of departments and offering efficiency by processing a large volume of transactions at reduced costs (Schulz \& Brenner, 2010). Notwhithstanding, recent studies suggest that these relocations can cause adverse effects on integration, for example, in the control and quality of the relationships between managers and head office, impacting on motivational and attitudinal aspects (Ishzaka \& Blakiston, 2012).

These studies have addressed the problem in terms of the costs related to relocation decisions and the organizational performance of these decisions, ignoring adverse effects, their impacts on the individual, and the use of psychological approaches to understand their effects (Kuntz \& Roberts, 2014; Richter \& Bruhl, 2017). Thus, the following research question arises: what are the impacts of the enabling performance measurement system, via psychological empowerment, on task performance and job satisfaction in an SSC? This study aims to analyze the impacts of the PMS with enabling characteristics, mediated by psychological empowerment, on task performance and job satisfaction in an SSC.

The studies on psychological empowerment have focused on management levels in companies (Yuliansyah \& Khan, 2015). When listing the antecedents and consequences associated with empowerment, Spreitzer (1995) indicated the need to also confirm the relationship at the operational level (lower-level employees). However, the number of studies for this level of analysis is limited (Yuliansyah \& Khan, 2015). It should also be verified how these relationships are structured in service providing companies and in different organizational designs (Chenhall, 2003). A different way of organizing the operations of a company are through SSCs (Bergeron, 2003), the focus of this study, in which the main hypothesis is that enabling PMSs mediated by psychological empowerment are positively associated with task performance and job satisfaction of individuals at the operational level. The aim is to contribute with evidence that using an enabling PMS favors the balance needed between levels of formal control and psychological empowerment in task performance.

The SSC structure can provide new evidence for the discussion on psychological empowerment, as it concerns decentralized units in the hierarchy of an organization, but which are highly dependent on resources from other units, meaning they have little autonomy (Bergeron, 2003). SSCs are geared towards seeking high operational efficiency, through standardized processes and service levels that are pre-agreed with the areas of the organization that have transferred their administrative activities to the SSC. The use of detailed working manuals is therefore recurrent (Bergeron, 2003), which can interfere in the individuals' sense of control and in the PMS, as well as impacting task performance and job satisfaction.

\section{THEORETICAL FRAMEWORK}

In the work environment, empowerment involves two distinct dimensions: (i) sociostructural, which concerns the contextual factors that enable the emergence of empowerment, such as practices, policies, and structures, and (ii) psychological, involving individuals' perceptions of empowerment in light of the practices, policies, and structures that surround them (Spreitzer, 2008). Thus, it is possible to define psychological empowerment as a psychological state experienced by individuals that indicates the success of the structural conditions of empowerment.

Empowerment is related with individuals' access to the tools of power mentioned by Kanter (1977), defined as opportunities, resources, information, and support (Spreitzer, 2008). From this perspective, power means having control over organizational resources and the 
individuals' possibilities for taking decisions that are relevant to their role or job (Spreitzer, 2008). From this viewpoint, a PMS can be understood as an element of sociostructural empowerment, since it concerns a management practice that involves decisions about the use and control of resources, the establishment of goals, changes in points of reference, feedback and feedforward information, and aspects of tasks, among others (Birnberg et al., 2006; Franco-Santos et al., 2012), which are often related to opportunities, resources, information, and support.

This relationship between PMS and psychological empowerment could be stimulated with the use of enabling PMSs, which can be understood as those that enable users more interaction, learning, use of skills, and an understanding of their logic, via the characteristics of repair, flexibility, internal transparency, and global transparency (Van Der Hauwaert \& Bruggeman, 2015). To stimulate empowerment, organizations can alter their structure, processes, policies, and practices in a way that incentivizes the use of high involvement systems, which includes participative decision making, performance systems based on knowledge and skills, and open flow information systems as a way of increasing access to opportunities, information, support, and resources between all hierarchical levels (Spreitzer, 2008).

Birnberg et al. (2006) show that the psychological studies on accounting practices have indicated that informational and motivational elements derived from such practices can influence the way individuals regulate their efforts and process information, in a way that is reflected in their levels of performance and satisfaction. Thus, it is suggested that an enabling PMS may be positively associated with job satisfaction and task performance via psychological empowerment. It follows that both motivational and informational effects can occur within the scope of such systems, since they stimulate subjective processes and influence the behavior of individuals via cognitive, motivational, and social mechanisms derived from the use of information for monitoring, measurement, and performance assessment activities, as indicated by the studies from Hall (2008) and Marginson et al. (2014), and they also enable greater individual involvement with the power mechanisms from Kanter (1977).

\subsection{Enabling PMS and Task Performance}

A PMS is characterized as a formal organizational control (Simons, 1992) with a range of financial and non-financial, informational, and assessment indicators, connected by a causal relationship between indicators and objectives, shaped according to the context and used to calculate the performance of a company at all its levels, as well as enabling individual learning and development (Franco-Santos et al., 2012). The control is based on two main concerns: (i) the design of the informational system and accountability, that is, the operating rules, which refer to the activities that the individuals carry out in an organization; and (ii) the behavior or enforcement rules, which should motivate the individual towards the organizational objectives (Demartini, 2014).

In this context, the concept of bureaucratic formalization (Adler \& Borys, 1996) suggests that, as in the design of systems and machines, the design of organizational processes should be characterized both by a fool-proofing logic and by a usability logic. Adler and Borys (1996) suggested a reanalysis of bureaucracy based on the concern about the type of bureaucracy instituted in companies. The authors retrieve the dimensions that compose a system for the user and apply them in the organizational area to explain the enabling characteristics, as presented in Table 1 . 
Table 1

Dimensions of enabling systems

\begin{tabular}{ll}
\hline \multicolumn{1}{c}{ Dimensions } & \multicolumn{1}{c}{ Description } \\
\hline Repair & $\begin{array}{l}\text { This is the ease with which a system can be repaired. This characteristic enables the users themselves } \\
\text { to repair the process instead of having their work interrupted because of a flaw or impasse. }\end{array}$ \\
\hline Internal transparency & $\begin{array}{l}\text { The logic behind the internal functioning and information about the status of the system are available } \\
\text { and are presented in an intelligible way for the user, who can correct errors. }\end{array}$ \\
\hline Global transparency & $\begin{array}{l}\text { This refers to the intelligibility of the system. It is the ability of the system to provide the users with } \\
\text { a range of information on the state of the entire production process. }\end{array}$ \\
\hline Flexibility & $\begin{array}{l}\text { This offers and suggests options for the user to decide. Flexible systems enable the user to modify } \\
\text { the interface and add functionalities to meet specific demands. }\end{array}$ \\
\hline
\end{tabular}

Source: Adapted from Adler and Borys (1996).

The processes that follow the usability logic are categorized as enabling formalization and the four characteristics are indicated in Table 1. These are designed so that employees are able to deal with the contingencies of their work, by stimulating the resolution of problems using their abilities and intelligence, with more open processes and exposure to their underlying logic, in a relationship that enables the development of learning (Adler \& Borys, 1996). Within this logic, problems are inevitable and it is desirable to offer mechanisms that support their resolution instead of exerting efforts in the elaboration of error-proof processes (Adler \& Borys, 1996).

In contrast, the processes designed using the foolproofing logic are typified as coercive formalization, focusing on compliance with rules and procedures, and they aim to obtain employee effort by imposing norms and monitoring their activities. Employees are seen as a possible source of problems and the processes therefore aim to mitigate the possibility of their occurrence (Adler \& Borys, 1996).

A PMS with enabling characteristics allows users to observe the cause and effect relationship of their activities both in local processes and in the overall company result, it offers customization of indicators for specific situations, and corrects processes that have presented problems. Such aspects increase the possibility for learning since they stimulate the users' understanding with regards to the logic of the process and it offers information about the degree to which goals are achieved, which can raise task performance (Hall, 2008; Mahama \& Cheng, 2013). The first hypothesis is thus formulated:

$\mathrm{H}_{1}$ : enabling PMSs are positively associated with task performance.

\subsection{Enabling PMS and Psychological Empowerment}

Based on the ideas of Conger and Kanungo (1988), Thomas and Velthouse (1990) elaborated a framework that defines psychological empowerment as the intrinsic motivation of tasks that occurs via four cognitions or mental states that shape the individual's orientation with regards to his/her role at work and which are susceptible to the influence of the work environment. Spreitzer (2008) highlights that for individuals to experience the feeling of psychological empowerment, the four dimensions shown in Table 2 need to arise; otherwise its effects will be limited.

Table 2

Dimensions of psychological empowerment

\begin{tabular}{ll}
\hline \multicolumn{1}{c}{ Dimension } & \multicolumn{1}{c}{ Description } \\
\hline Meaning & This implies consistency between job requirements and individual beliefs, values, and behaviors. \\
\hline Competence & $\begin{array}{l}\text { This refers to the level of self-efficacy of the individual with regards to his/her work. It concerns } \\
\text { belief in the individual skills to adequately carry out the work activities. }\end{array}$ \\
\hline Self-determination & $\begin{array}{l}\text { This concerns the individual's feelings of choice and control over his/her work and is reflected } \\
\text { in the autonomy to decide with regards to the methods, effort, and rhythm of his/her activities. }\end{array}$ \\
\hline Impact & $\begin{array}{l}\text { This corresponds to the individual's belief regarding his/her ability to influence important } \\
\text { issues in the organization, such as its results. }\end{array}$ \\
\hline
\end{tabular}

Source: Adapted from Spreitzer (1995, 2008). 
As already highlighted, an enabling PMS affects contextual factors present in the practices that characterize sociostructural empowerment, for example the need for a system with an open logic, incentives for involvement, and access to information and opportunities. In this sense, enabling controls offer more interaction between the system and its users since they allow them to make corrections and adaptations, they institute the need to offer transparency, both at the individual level and in the general impacts of their activities, and they offer flexibility by designing a system that gives support to the user (Adler \& Borys, 1996).

Psychological empowerment, in turn, derives from conditions in which employees feel that their work has meaning, from conditions for them to adequately carry out their activities, autonomy for them to decide what to do and how, and the feeling that they can impact their work environment (Spreitzer, 2008). The aspects pointed out offer indications that there is an alignment between both, given that the characteristics of an enabling system are aligned with the feelings that form part of the concept of psychological empowerment. In addition, according to Hall (2008), characteristics of a PMS that increase its ability to offer relevant information can positively impact and reinforce the four dimensions of psychological empowerment since they increase the ability for individual initiative, they provide greater knowledge regarding performance and the abilities needed to carry out the tasks, and they make individuals feel valued. Considering that an enabling PMS includes, among its prerogatives, increasing individual involvement, as well as access to information that is considered relevant, the second research hypothesis was formulated:

$\mathrm{H}_{2}$ : enabling PMSs are positively associated with psychological empowerment.

\subsection{Enabling PMS and Job Satisfaction}

The relationship between PMS and job satisfaction has been explained via the mediating variables, for example trust in the supervisor and fairness in the assessment procedures (Franco-Santos et al., 2012). However, it is argued in the study that there can be elements in an enabling PMS with similarities to other concepts that involve the dissemination of information, encouragement of the use of skill, and learning, which can explain a possible direct association between enabling PMSs and job satisfaction. One example is structural empowerment, which is normally employed in research on high involvement practices and high performance human resources practices (HPHRP).
The increase in structural empowerment perceived by employees would come about via access to information, resources needed to carry out the work, support, and opportunities for learning and growth (Laschinger, Finegan, Shamian, \& Wilk, 2001). In contrast, enabling PMSs stimulate the dissemination of information and the occurrence of feedback, identifying problems and their solution through the employee's ability, identification of learning opportunities, and help in prioritizing actions, and with this they provide employees with mechanisms to better carry out their work and shape an environment that favors their development (Wouter \& Wilderon, 2008).

Laschinger, Finegan, Shamian, and Wilk (2004) verified that elements of structural empowerment are directly related with job satisfaction, such as: acquiring new skills and using one's abilities to carry out tasks (opportunity); having access to information on the status of activities, knowing the objectives and values of the organization (information); obtaining performance feedback and help in resolving problems (support); and having time for work demands and obtaining temporary help when necessary (resources). This suggests that individuals exposed to better structural conditions with more access to the support and resources needed to carry out their activities would have greater job satisfaction (Laschinger et al., 2004).

Kanter (1977) suggests that individuals who do not have access to resources, information, support, and opportunity experience feelings of impotence that impede their perception of psychological empowerment. This can lead to feelings of frustration and failure since they feel stagnated in their work and without mobility (Spreitzer, 2008). The use of an enabling PMS can make employees feel that they have the resources and the support needed to perform their tasks and thus obtain job satisfaction, since this PMS potentially enables access to the elements mentioned by Kanter (1977) and Laschinger et al. (2004), such as access to information, support, and learning.

In addition, studies that address elements of HPHRP have found positive associations with job satisfaction. HPHRPs constitute human resource management practices designed to promote the well-being and commitment of employees (Mostafa \& Gould-Willians, 2014). Although there is no agreement regarding what practices constitute HPHRP, they are considered to promote the ability of employees, communication, opportunity, and motivation (Mostafa \& Gould-Willians, 2014), which are aspects that share a similarity with enabling PMSs.

PMSs are commonly associated with performance pay policies and career development, so a system that enables users to understand the logic behind their evaluations 
enables its use as a means of supporting their activities, it opens up room for learning, and can provide positive results in attitudinal and behavioral aspects (Wouters \& Roijimans, 2011). The third hypothesis was thus formulated:

$\mathrm{H}_{3}$ : enabling PMSs are positively associated with job satisfaction.

\subsection{Psychological Empowerment and Task Performance}

Studies have observed that psychological empowerment is positively related to managerial effectiveness (Spreitzer, 1995), employee effectiveness (Spreitzer, Kizilos \& Nason, 1997), and task performance (Mahama \& Cheng, 2013). Liden et al. (2000) verified that in a sample of employees from the base of the hierarchy of a services company in the United States the competence dimension of psychological empowerment was positively and significantly associated with job performance. In a sample of Australian managers from manufacturing units, Hall (2008) verified that the meaning dimension was associated with performance. Marginson et al. (2014) observed a significant and positive relationship between the performance of non-financial measures and the competence, meaning, and self-determination dimensions of psychological empowerment in a sample of managers from a multinational telecommunications company.

Studies on this topic have observed that task performance derives from different characteristics in each one of the four dimensions of psychological empowerment: (i) competence relates to greater effort, high expectations of goals, and persistence in challenging situations; (ii) meaning relates to a high commitment and concentration of energy in the task; (iii) self-determination relates to learning, interest in the activity, and resilience; and (iv) impact relates to facing difficult situations and high task performance (Mahama \& Cheng, 2013; Spreitzer, 1995).

Psychological empowerment as a unique construct was investigated by Chiang and Hsieh (2012), who verified a positive and significant association with the performance of hotel workers in Taiwan. These authors argued that psychological empowerment leads individuals to trust in their ability to meet the demands of their work and have fewer doubts about themselves and their work, which results in better performance.

Laschinger et al. (2004) explain that individuals with a perception of psychological empowerment react to adversities in their work, show persistence and ingenuity in order to overcome obstacles, seek to influence the objectives and operational procedures that can improve the quality of the results, anticipate problems, and react better to risks and uncertainties of the environment. Psychological empowerment can also increase resilience, initiative, and concentration, as well as triggering the perception that individuals are able to influence their work, leading to proactive behavior towards their activities, which translates into effective task performance (Mahama \& Cheng, 2013; Spreitzer, 1995, 2008). From this perspective, the fourth research hypothesis was elaborated:

$\mathrm{H}_{4}$ : psychological empowerment is positively associated with task performance.

\subsection{Psychological Empowerment and Job Satisfaction}

Bordin, Bartram, and Casimir (2006) argue that all the dimensions of psychological empowerment are susceptible to positively impacting job satisfaction. Impact increases job involvement since individuals can visualize the effects of their actions on organizational results (Bordin et al., 2006), self-determination allows greater control over their routine (Spreitzer, 2008), competence indicates that individuals have the ability and knowledge needed to carry out their activities, which enables them to approach them adequately and assertively (Bordin et al., 2006), and meaning indicates that employees are dedicated to achieving objectives that are aligned with their values (Spreitzer, 2008).

Holdsworth and Cartwright (2003) researched employees in the call center of an English company and observed that the impact and self-determination dimensions are positively related with job satisfaction. Liden et al. (2000) verified that for employees at the base of the hierarchy of a large North American services company the meaning dimension was positively associated with job satisfaction. By operationalizing psychological empowerment in a single construct, He, Murrmann, and Perdue (2010) verified that among employees of a North American services organization those with the greatest psychological empowerment reported the highest job satisfaction.

When evaluating the influence of empowerment in the work environment, Liden et al. (2000) argued that it is reflected in the perception of job satisfaction when people: (i) are involved in work activities that have meaning; (ii) have a sense of control over their work; (iii) are involved in decision-making processes; and (iv) feel able to carry out their roles. Wang and Lee (2009) argued that characteristics of a job that promote feelings of psychological empowerment can foster emotional states that are able to influence satisfaction. 
Higher levels of job satisfaction, with regards to career, rewards, relationships with peers and superiors, and the nature of the work, have been indicated by employees who feel that: (i) their work has meaning for them; (ii) they have the skills needed to carry out their activities; (iii) they can make choices related to their work routine; and (iv) they recognize the impacts of their actions on the organization (Spreitzer, 2008). This association occurs since individuals that experience psychological empowerment perceive the fulfillment of their needs in a more intrinsic way (Seibert, Wang \& Cortright, 2011). This thus leads to the fifth research hypothesis:

$\mathrm{H}_{5}$ : psychological empowerment is positively associated with job satisfaction.

\subsection{Enabling PMS, Psychological Empowerment, and Task Performance}

Drake, Wong, and Salter (2007) analyzed elements of PMSs related to psychological empowerment and performance with the aim of understanding the joint effects of the two elements of a PMS on employees at the operational level: feedback and remuneration schemes. Evidence from the study indicated that feedback affects performance via the impact dimension of psychological empowerment and remuneration schemes based on earnings can negatively influence the competence and self-determination dimensions.

Regarding the enabling characteristics, Mahama and Cheng (2013) verified the relationship between enabling systems and psychological empowerment restricted to enabling costing systems. Despite not finding a direct association between these constructs, they found that their association can occur indirectly via the intensity of use of the system.

Hall (2008) investigated the role of psychological empowerment and clarity of roles in the relationship between the comprehensibility of a PMS and performance. He inferred that the comprehensibility of the informational characteristics of the PMS can influence manager performance, but an influence on performance was only found via the meaning dimension of empowerment. Yuliansyah and Khan (2015) replicated the model from Hall (2008), changing the context from managers of Australian industries to operational level employees from the financial services area in Indonesia. Besides the meaning dimension, the competence and selfdetermination dimensions contributed to the relationship between PMS and performance, which reinforces the impacts of the context on the investigations regarding psychological empowerment.
Seibert et al. (2004) observed that the impacts of management practices related to the sharing of information, autonomy to explore limits, responsibility and accountability of teams for performance, and job satisfaction depend on the perception of employees with respect to these practices, which implies investigating ways of influencing the psychological aspect of organizational practices.

Therefore, an enabling PMS can influence task performance via psychological empowerment since studies have indicated a relationship between management practices that stimulate the sharing of information, decentralization, training, and feedback, with an increase in the control, knowledge, skills, and motivation of employees, enabling better behavioral results such as task performance and the achievement of organizational objectives (Seibert et al., 2011). Enabling PMSs, seen as an element of structural empowerment, constitute an organizational component that can lead employees to the perception of psychological empowerment, and indirectly to task performance. Thus, the sixth research hypothesis was formulated:

$\mathrm{H}_{6 \mathrm{a}}$ : enabling PMSs mediated by psychological empowerment are positively associated with task performance.

\subsection{Enabling PMS, Psychological Empowerment, and Job Satisfaction}

Management practices that involve elements such as the sharing of information, decentralization, participative decision making, extensive training, and contingent compensation can affect the four dimensions of psychological empowerment since they increase the quantity of information and autonomy of employees in their work and they broaden the knowledge and skills related to the work activities and motivation the individuals, enabling them to fulfill their intrinsic needs and raising their job satisfaction (Seibert et al., 2011).

Bordin et al. (2006) found a positive association between access to information and job satisfaction in a sample of information technology (IT) workers in Singapore. Chan, Nadler, and Hargis (2015) observed a positive association between psychological empowerment and job satisfaction in a sample of sports material distribution workers in the United States. Taken together, the findings may indicate an indirect relationship between the variables. Studies from Laschinger et al. $(2001,2004)$ of workers from the healthcare field have indicated that work environment conditions related to information, skills, knowledge, learning, feedback, and support exert an influence on 
job satisfaction via psychological empowerment.

Liden et al. (2000) found evidence that the characteristics of the work, such as task identity, meaning of tasks, and feedback, are indirectly related with job satisfaction via the meaning and competence dimensions. The mechanisms underlying this relationship cover three critical psychological states associated with job characteristics: meaning experienced, responsibility experienced, and knowledge regarding the results.

Seibert et al. (2004) verified that psychological empowerment can act as a mediator of key organizational practices (sharing of information, autonomy, and accountability of teams) and of job satisfaction. They highlight that the sharing of information implies providing information on costs, productivity, quality, and financial performance of employees, while autonomy includes organizational practices and structures that enable autonomous actions such as a clear vision and objectives, work procedures, and areas of responsibility.

The evidence provided by the studies enables it to be inferred that an enabling PMS has characteristics related to the sharing of information, clarity of objectives and goals, and the possibility for learning and using skills that are able to influence job satisfaction, by enabling the individual to experience feelings of psychological empowerment. In this sense, the seventh research hypothesis was elaborated:

$\mathrm{H}_{6 \mathrm{~b}}$ : enabling PMSs mediated by psychological empowerment are positively associated with job satisfaction.

Figure 1 illustrates the representation of the research constructs with the relationships proposed in the hypotheses formulated in this study. According to the figure, the focus of the investigation is on the impacts of enabling PMSs, composed of the repair, flexibility, internal transparency, and global transparency dimensions in task performance and in job satisfaction, via the psychological empowerment composed of the self-determination, competence, impact, and meaning dimensions in an SSC.

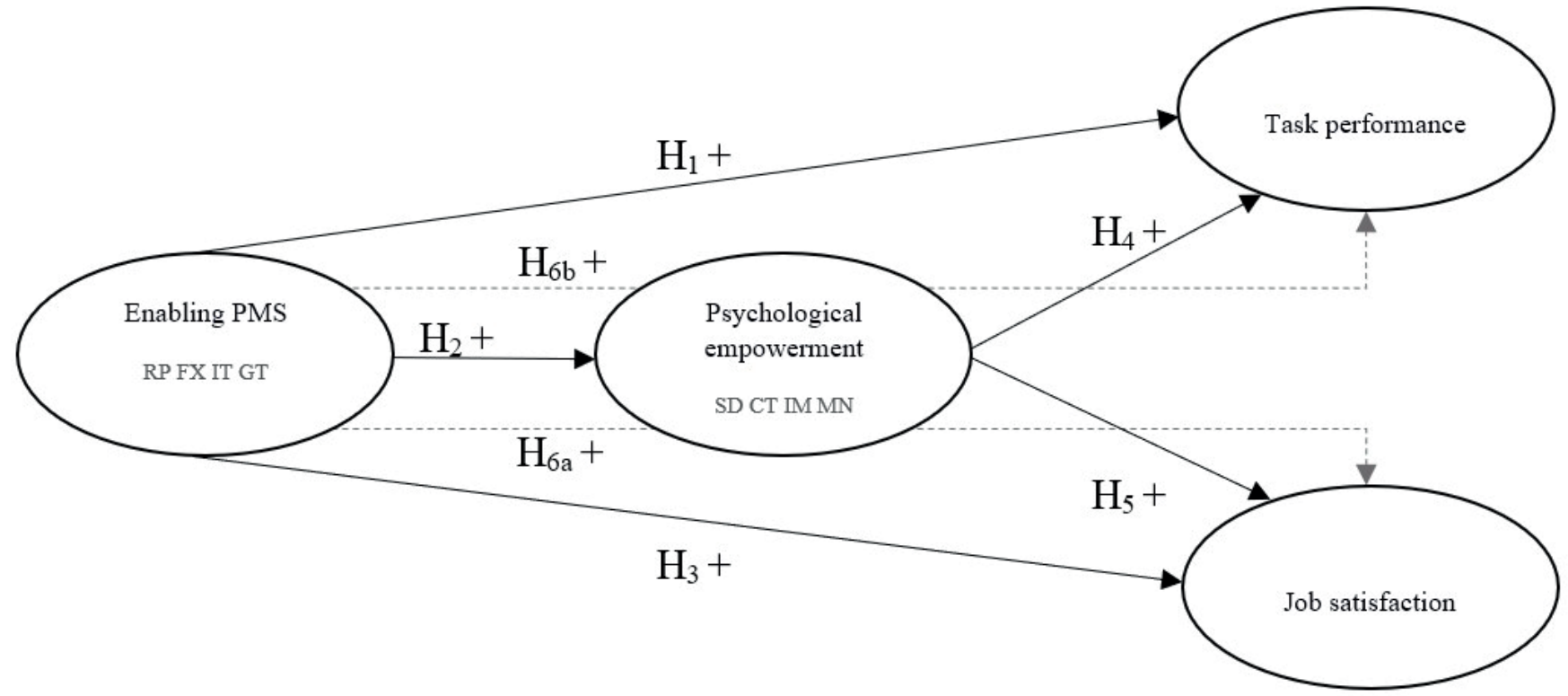

Figure 1 Theoretical model of the study

$S D=$ self-determination; $C T=$ competence; $F X=$ flexibility; $I M=$ impact; $P M S=$ performance measurement system; $R P=$ repair; $M N=$ meaning; $G T=$ global transparency; $I T=$ internal transparency.

Source: Elaborated by the authors. 


\section{RESEARCH METHODOLOGY}

This study was carried out using a survey of operational level employees in an SSC. An SSC was identified in which the operational staff had access to performance assessment mechanisms and where there were no differences between the sectors regarding the form of access and assessment. The SSC was selected by sending invites containing the study prospectus. After identifying the potential participant, contacts were made via telephone and presentially in order to detail the research.

The SSC that was the object of study is located in southern Brazil and carries out back office activities in the structure of a company whose head office is in Europe. All in all, the overall structure of the SSC has 1,900 employees who attend to 90 units in 25 countries. The back office unit of the Brazilian SSC, the object of this study, attends to approximately $16 \%$ of the total volume of operations, with 125 operational employees (41 analysts and 84 assistants) who act in direct contact with the clients, in this case other units of the company, offering administrative, financial, and accounting services. The participation of 88 respondents was obtained, who were spread between the procure-to-pay (63.64\%), record-toreport $(20.45 \%)$, order-to-cash (11.36\%), and support (4.55\%) sectors. These sectors correspond to all the areas that provide the unit's services.

\subsection{Constructs and Research Instrument}

Table 3 reports the constructs, their operational definition, the number of assertions used in each dimension in the questionnaire, and the respective references.

Table 3

Research construct

\begin{tabular}{|c|c|c|c|c|}
\hline Constructs & Variables & Operational definition & Questions & References \\
\hline \multirow{4}{*}{ Enabling PMS } & Repair & $\begin{array}{l}\text { Possibility for the users themselves to } \\
\text { repair a process instead to forcing the } \\
\text { interruption of the work when faced } \\
\text { with a flaw or impasse. }\end{array}$ & 3 & \multirow{4}{*}{$\begin{array}{l}\text { Van Der Hauwaert } \\
\text { and Bruggeman } \\
\qquad(2015)\end{array}$} \\
\hline & Internal transparency & $\begin{array}{l}\text { The logic behind the functioning of a } \\
\text { process and the information about its } \\
\text { status are available and are presented } \\
\text { in an intelligible way. }\end{array}$ & 3 & \\
\hline & Global transparency & $\begin{array}{l}\text { Availability of information for the } \\
\text { user regarding the state of the entire } \\
\text { production process. }\end{array}$ & 3 & \\
\hline & Flexibility & $\begin{array}{l}\text { Possibility for employees to modify } \\
\text { processes to attend to specific demands. }\end{array}$ & 3 & \\
\hline \multirow{4}{*}{$\begin{array}{l}\text { Psychological } \\
\text { empowerment }\end{array}$} & Self-determination & $\begin{array}{l}\text { Autonomy of the individual to decide } \\
\text { on the methods, efforts, and rhythm of } \\
\text { the activities. }\end{array}$ & 3 & \multirow{4}{*}{$\begin{array}{l}\text { Spreitzer } \\
(1995)\end{array}$} \\
\hline & Competence & $\begin{array}{l}\text { Individual abilities to adequately } \\
\text { develop the work activities. }\end{array}$ & 3 & \\
\hline & Impact & $\begin{array}{l}\text { Influence of the individual over strategic, } \\
\text { administrative, and operational results. }\end{array}$ & 3 & \\
\hline & Meaning & $\begin{array}{l}\text { Coherence between job requirements } \\
\text { and individual beliefs, values, and } \\
\text { behaviors. }\end{array}$ & 3 & \\
\hline Job satisfaction & Job satisfaction & $\begin{array}{l}\text { Emotional response to physical and } \\
\text { social conditions in the locations and } \\
\text { job tasks. }\end{array}$ & 6 & Tarrant and Sabo (2010) \\
\hline Task performance & Task performance & $\begin{array}{l}\text { Level with which the individuals carry } \\
\text { out the specific tasks of their job. }\end{array}$ & 6 & Mahama and Cheng (2013) \\
\hline
\end{tabular}

PMS = performance measurement system.

Source: Elaborated by the authors. 
The research instrument was elaborated using assertions already validated in other studies, but their joint use is specific to this study. Although the concept of enabling PMS has been used before, the studies have done so in a qualitative way (Jordan \& Messner, 2012; Mundy, 2010; Wouters \& Roijmans, 2011; Wouters \& Wilderon, 2008). Thus, in order to capture the repair, internal transparency, global transparency, and flexibility dimensions that compose the enabling controls, the instrument from Van Der Hauwaert and Bruggeman (2015) was used, which is the only one found up until then that proposed studying enabling PMSs using a quantitative approach. Based on the studies from Adler and Borys (1996) and Ahrens and Chapman (2004), they elaborated a questionnaire to investigate PMSs, reporting the procedures used to validate the instrument, such as carrying out factor analysis and adjustment indices.

The self-determination, competence, impact, and meaning dimensions that compose psychological empowerment were captured using the research instrument from Spreitzer (1995), developed based on the studies from Conger and Kanungo (1988) and Thomas and Velthouse (1990). This questionnaire has already been replicated in studies on PMSs by Hall (2008) and Yuliansyah and Khan (2015).

In order to capture the one-dimensional construct of job satisfaction, the Job Satisfaction Index from Tarrant and Sabo (2010) was used. This instrument was elaborated to evaluate the satisfaction of workers in the healthcare field. Its version in Portuguese was validated by Palomino and Frezatti (2016) in a study on conflict and ambiguity of roles involving Brazilian controllers. In order to capture the one-dimensional construct of tasks performance, the questionnaire from Mahama and Cheng (2013) was used, which is a reduced version of the instrument from Kathuria and Davis (2001) conceived based on the study from Carroll and Schneier (1982).

The survey instrument was based on a seven-point Likert scale, which is consistent with the original instruments. The instrument was customized, paying attention to the vocabulary used in the unit, in order to avoid ambiguities. The survey was applied presentially in the company in February 2016. The day before the data were gathered by the human resources area, a communication was sent out to the employees asking for their participation and raising their awareness about the content of the study.

The data gathered were tabulated and subjected to statistical treatment in the Statistical Package for the Social Sciences 21 (SPSS) and Smart PLS 3 software packages. None of the 88 questionnaires presented missing values.
The relationships proposed in the theoretical model were analyzed using partial least squares structural equation modeling (PLS-SEM). This multivariate analysis technique enables a set of simultaneous relationships to be tested based on the explanation of the variance between the model constructs (Hair, Hult, Ringle \& Sarstedt, 2016). Its application is considered appropriate in exploratory studies that seek to develop theories (Hair et al., 2016).

\subsection{Construction of the Hierarchical Model}

The model used employs second order variables. Higher order models or hierarchical component models are used when the aim is to analyze constructs at higher levels of abstraction. Second order latent variables (LVs) are created based on first order constructs that refer to their attributes (Hair et al., 2016). In addition, by reducing the quantity of relationships in the structural model, the PLS path model becomes more harmonious and comprehensible (Hair et al., 2016).

The hierarchical model in question is type II reflexiveformative. The two-stage approach was chosen as it is the most indicated in complex path models in which there are second order variables in an endogenous position (Ringle, Sarstedt \& Straub, 2012). Becker, Klein, and Wetzels (2012) indicated that the two-stage approach is one of the best approaches and offers a useful alternative for studies that seek to only analyze second order relationships.

The enabling PMS and psychological empowerment constructs were obtained based on the scores for the four dimensions that make them up. The enabling PMS integrates the repair, flexibility, internal, and global transparency dimensions, and their joint analysis based on one second order variable resembles the idea of general perception of the enabling controls, as used by Mahama and Cheng (2013). However, the authors used a onedimensional scale, while in this study the four dimensions are recognized separately along with a general perception based on a second level of abstraction.

Psychological empowerment, formed of competency, self-determination, impact, and meaning, is a concept that proposes the perception of its four dimensions simultaneously, forming a gestalt (Spreitzer, 2008); that is, the isolated dimensions are not enough to translate psychological empowerment. In a discussion about the statistical validity of using this construct segregated into its dimensions or in combination, Seibert et al. (2011) support the operationalization of the construct in combination, which motivated its use in this study as a second order variable.

Although the enabling PMS and psychological empowerment variables are second order, for the purposes 
of evaluating the measurement and structural models it is necessary to consider the results obtained with the first order model (Becker, Klein \& Wetzels, 2012). For this reason, the results obtained with the model in the first stage of the two-stage approach are presented below; that is, detailing each dimension of the constructs measured.

\section{DESCRIPTION AND ANALYSIS OF THE RESULTS}

\subsection{Evaluation of the Measurement and Structural Model}

In the evaluation of the structural model, convergent validity, composite reliability, and discriminant validity are considered. To confirm the criteria recommended in the convergent validity, it was verified whether the indicators of each LV of the model share a common variance via an analysis of the factor loads of each indicator, of the average extracted variance (AVE) of the LVs, and the composite reliability and Cronbach's alpha, which indicate the internal consistency (Hair et al., 2016). Table 4 presents these final values. It is noted in this table that all the factors present higher values than the minimum recommended, of 0.50 for AVE and 0.70 for CC and Cronbach's alpha (Hair et al., 2016); that is, there is convergent validity and composite reliability in the proposed model.

Table 4

Convergent validity and consistency of the constructs

\begin{tabular}{lccc}
\hline \multicolumn{1}{c}{ Variables } & AVE & Composite reliability & Cronbach's alpha \\
\hline Repair & 0.807 & 0.926 & 0.882 \\
\hline Flexibility & 0.760 & 0.905 & 0.841 \\
\hline Internal transparency & 0.685 & 0.867 & 0.771 \\
\hline Global transparency & 0.707 & 0.879 & 0.794 \\
\hline Self-determination & 0.855 & 0.946 & 0.915 \\
\hline Competence & 0.843 & 0.941 & 0.906 \\
\hline Impact & 0.827 & 0.935 & 0.895 \\
\hline Meaning & 0.941 & 0.980 & 0.969 \\
\hline Job satisfaction & 0.754 & 0.948 & 0.934 \\
\hline Task performance & 0.633 & 0.911 & 0.883 \\
\hline
\end{tabular}

$A V E=$ average extracted variance.

Source: Elaborated by the authors.

Regarding the discriminant validity, which indicates how much one construct is individually distinct from the rest (Hair et al., 2016), the results of the cross-loadings matrix used in the variables were initially observed, indicating the inexistence of cross-loadings between the constructs of the model. Next, the criterion from Fornell and Larcker (1981) was verified, in which the square root of the AVE is compared with the correlation between the LVs. For there to be discriminant validity, it is recommended that the correlations between the constructs are greater than the square root of the AVE. Table 5 presents the values of the correlations between the variables and it is verified that none of the correlations between the constructs was greater than the square root of the AVE, indicating that there is discriminant validity (Fornell \& Larcker, 1981). Thus, the model fulfills the main validity assumptions (convergent and discriminant). Table 6 presents the results of the structural model. 
Table 5

Discriminant validity (Fornell \& Larcker, 1981)

\begin{tabular}{|c|c|c|c|c|c|c|c|c|c|c|}
\hline Variables & SD & CT & TP & FX & IM & RP & JS & MN & GT & IT \\
\hline Self-determination (SD) & 0.925 & & & & & & & & & \\
\hline Competence $(\mathrm{CT})$ & 0.281 & 0.918 & & & & & & & & \\
\hline Task performance (TP) & 0.350 & 0.383 & 0.795 & & & & & & & \\
\hline Flexibility (FX) & 0.521 & 0.089 & 0.359 & 0.872 & & & & & & \\
\hline Impact (IM) & 0.620 & 0.261 & 0.463 & 0.625 & 0.909 & & & & & \\
\hline Repair (RP) & 0.433 & 0.105 & 0.262 & 0.703 & 0.437 & 0.899 & & & & \\
\hline Job satisfaction (JS) & 0.492 & 0.040 & 0.420 & 0.622 & 0.530 & 0.456 & 0.869 & & & \\
\hline Meaning (MN) & 0.524 & 0.174 & 0.443 & 0.557 & 0.622 & 0.333 & 0.718 & 0.970 & & \\
\hline $\begin{array}{l}\text { Global transparency } \\
\text { (GT) }\end{array}$ & 0.495 & 0.084 & 0.346 & 0.774 & 0.530 & 0.738 & 0.626 & 0.518 & 0.841 & \\
\hline $\begin{array}{l}\text { Internal } \\
\text { transparency (IT) }\end{array}$ & 0.439 & 0.113 & 0.331 & 0.689 & 0.529 & 0.707 & 0.441 & 0.352 & 0.746 & 0.828 \\
\hline
\end{tabular}

Source: Elaborated by the authors.

Table 6

Results of the structural model

\begin{tabular}{|c|c|c|c|c|c|c|}
\hline Variables & $\mathbf{R}^{2}$ & $\mathbf{R}^{2}$ adjusted & $\mathbf{Q}^{2}$ & SRMR & $\mathbf{f}^{2}$ & VIF \\
\hline Repair & & & & & $0.000-0.025$ & 2.749 \\
\hline Flexibility & & & & & $0.000-0.134$ & 3.470 \\
\hline Internal transparency & & & & & $0.002-0.030$ & 2.830 \\
\hline Global transparency & & & & & $0.000-0.066$ & 3.748 \\
\hline Self-determination & 0.295 & 0.261 & 0.212 & 0.071 & $0.001-0.008$ & 1.862 \\
\hline Competence & 0.014 & -0.033 & -0.022 & 0.071 & $0.022-0.113$ & 1.128 \\
\hline Impact & 0.414 & 0.386 & 0.326 & 0.071 & $0.000-0.020$ & 2.448 \\
\hline Meaning & 0.360 & 0.329 & 0.319 & 0.071 & $0.041-0.329$ & 1.998 \\
\hline Job satisfaction & 0.623 & 0.585 & 0.445 & 0.071 & & \\
\hline Task performance & 0.338 & 0.271 & 0.172 & 0.071 & & \\
\hline
\end{tabular}

$S R M R=$ standardized root mean square residual VIF = variance inflation factor.

Source: Elaborated by the authors.

It is noted in Table 3 that the model's predictive accuracy for the job satisfaction and task performance dimension is moderate (Peng \& Lai, 2012), with $\mathrm{R}^{2}$ and $\mathrm{R}^{2}$ adjusted values that vary between $0.623 / 0.585$ and $0.338 / 0.271$, respectively. The $\mathrm{Q}^{2}$ values indicate whether the model has predictive relevance and should be higher than 0 (Peng \& Lai, 2012). Therefore, the competence dimension of psychological empowerment does not meet this criterion, besides presenting an $\mathrm{R}^{2}$ adjusted with a negative value, which indicates that its contribution to the model's explanatory and predictive ability is not satisfactory. However, competence composes the theoretical construct of the four dimensions of psychological empowerment (Spreitzer, 2008); thus, the decision was made to maintain it, since the focus of this study is on evaluating the paths for the second order variables.

The value of the square root of the standardized residuals, which is lower than 0.08 , indicates that the model fits the needs of the empirical data (Latan, Ringle \& Jabbour, 2016). The values of the size of the effects vary from non-existent for repair $\rightarrow$ job satisfaction $\left(\mathrm{f}^{2}=\right.$ 0 ), flexibility $\rightarrow$ competence $\left(f^{2}=0\right)$, global transparency $\rightarrow$ competence $\left(\mathrm{f}^{2}=0\right)$, and impact $\rightarrow$ job satisfaction, to medium effects, such as meaning $\rightarrow$ job satisfaction $\left(\mathrm{f}^{2}=\right.$ 
$0,329)$. Finally, the values of the variance inflation factor (VIF), which are lower than 5 for all the independent variables, indicate that there are no collinearity problems (Hair et al., 2016).

After evaluating the structural measurement model, the path coefficient was calculated with 5,000 interactions. Next, the bootstrapping technique was applied to evaluate the level of significance between the relationships of the constructs, using 5,000 subsamples, a bias-corrected and accelerated confidence interval, and a one-tailed test at a 5\% level of significance (Hair et al., 2016; Marginson et al., 2014). Based on the bootstrapping, the path values, $\mathrm{t}$-value, and p-value of each relationship were obtained, as shown in Table 7.

Table 7

Effects between the constructs

\begin{tabular}{lcccc}
\hline \multicolumn{1}{c}{ Relationship between the constructs } & Hypothesis & Value & t-value & p-value \\
\hline Enabling PMS $\rightarrow$ task performance & $\mathrm{H}_{1}$ & 0.0101 & 0.0599 & 0.4761 \\
\hline Enabling PMS $\rightarrow$ psychological empowerment & $\mathrm{H}_{2}$ & 0.6550 & 9.0215 & $0.0000^{* *}$ \\
\hline Enabling PMS $\rightarrow$ job satisfaction & $\mathrm{H}_{3}$ & 0.3145 & 3.2992 & $0.0005^{* *}$ \\
\hline Psychological empowerment $\rightarrow$ task performance & $\mathrm{H}_{4}$ & 0.4008 & 2.5414 & $0.0055^{*}$ \\
\hline Psychological empowerment $\rightarrow$ job satisfaction & $\mathrm{H}_{5}$ & 0.4696 & 4.9998 \\
\hline Enabling PMS $\rightarrow$ psychological empowerment $\rightarrow$ task performance & $\mathrm{H}_{6 \mathrm{a}}$ & 0.2626 & 2.4920 & $0.0000^{* *}$ \\
\hline Enabling PMS $\rightarrow$ psychological empowerment $\rightarrow$ job satisfaction & $\mathrm{H}_{6 \mathrm{~b}}$ & 0.3076 & 4.3224 & $0.0064^{*}$ \\
\hline PMS & & & & $0.0000^{* *}$ \\
\hline
\end{tabular}

PMS = performance measurement system .

*, **: 0.01 and 0.001 significant, respectively.

Source: Elaborated by the authors.

From the results in Table 7, of the seven hypotheses formulated only one did not have values that enabled it to be sustained. Their possible implications are discussed in the next section.

\subsection{Discussion of the Results}

Hypothesis $\mathrm{H}_{1}$, which foresees a positive and significant relationship between an enabling PMS and task performance, was not supported ( $p$-value $>0.05$ ). Therefore, it cannot be affirmed that a PMS with clear information on goals, objectives, vision, and mission, and that is transparent with respect to the causal relationships between these elements and the actions of employees, both locally and in the overall structure of the company, or that enables problems to be identified and solved in an active way, can lead to better task performance.

Goal Setting Theory proposes that goals can be considered as consciously proposed intentions, aims, desired results, or performance standards or targets that affect performance by directing attention to a selection of appropriate strategies, knowledge, and actions (Marginson et al., 2014). Thus, an enabling PMS was expected to be able to trigger the processes foreseen by this theory to the point of influencing performance. However, the result for $\mathrm{H}_{1}$ corroborates Bandura (1986), for whom the motivation to carry out activities does not only depend on the goals in themselves, but also on the need to obtain a personal sense of satisfaction in relation to them.

Hypothesis $\mathrm{H}_{2}$, which foresees a significant and positive relationship between an enabling PMS and psychological empowerment, was supported ( $p$-value $<0.001$ ). It indicates that making a PMS available that is capable of stimulating the interaction between individuals and their environment in a way that promotes the use of their skills and learning, as well as offering clear information that supports their work, leads to employees reporting greater feelings of intrinsic motivation; that is, they perceive the work environment in a positive way and consider that they have the skills needed to carry out their work and are able to influence the results of their organization, they feel they have control over the distribution of their tasks in their routine, and they see their work as being aligned with their personal values.

Hall (2008) and Yuliansyah and Khan (2015) observed a positive association between PMS comprehensibility and psychological empowerment. Marginson et al. (2014) found that PMS usage styles, which involve the way of using information and making it available, are positively associated with psychological empowerment. However, Mahama and Cheng (2013) did not find any direct positive relationship between any dimension of psychological empowerment and enabling characteristics of the costing system. Just like PMSs, costing systems provide essential 
information about the activities of employees and an organization, but in the case of the costing system this was only related with psychological empowerment via the intensity of use of the system, which suggests that the understanding of its semantic level varies (DeLone \& McLean, 2003), possibly due to the complexity involved in the costing information (Mahama \& Cheng, 2013).

Hypothesis $\mathrm{H}_{3}$, which foresees a significant and positive relationship between an enabling PMS and job satisfaction, was supported ( $\mathrm{p}$-value $<0.001$ ). It indicates that individuals that have greater access to information about performance, about the effects of their work on an organization, and that can rely on the PMS to use their experience and broaden their knowledge, have their individual needs related to the work fulfilled, and thus report higher levels of satisfaction. Kanter (1977) argues that in the absence of the information needed to carry out their tasks individuals might experience negative feelings such as frustration, which would lead to an increase in tension at work and negatively interfere with their satisfaction (Spreitzer, 1995, 2008).

Hypothesis $\mathrm{H}_{4}$, which foresees a significant and positive relationship between psychological empowerment and task performance, was supported ( $\mathrm{p}$-value $<0.01$ ). This result indicates that intrinsic motivation at work, reflected in the recognition that the employees have the necessary requirements to meet the demands of their task, control over their routine, the ability to contribute with results obtained by their department or organization, and coherence between organizational and personal values, leads them to have positive conducts in their work, with greater persistence, assertiveness, concentration, and resilience, which can result in them obtaining better results in their activities.

However, studies that address the relationship between psychological empowerment and performance have shown different results regarding the importance of the dimensions. Mahama and Cheng (2013) observed positive relationships between competence, meaning, selfdetermination, and manager performance. Hall (2008) identified positive impacts only for the meaning dimension on management performance. When investigating operational staff from the services area, Yuliansyah and Khan (2015) observed positive relationships between the competence and self-determination dimensions and performance and negative ones between the impact dimension and performance.

Hypothesis $\mathrm{H}_{5}$, which foresees a significant and positive relationship between psychological empowerment and job satisfaction, was supported (p-value $<0.001$ ). It indicates that job satisfaction is susceptible to influence depending on how much individuals feel their beliefs are coherent with the activities they carry out, there is discretion regarding the way of organizing and prioritizing their activities, the demands of the work can be met by their skills and knowledge, and they see the impacts of their actions on the performance of their unit. Thomas and Velthouse (1990) state that low levels of meaning are linked to low job satisfaction and feelings of apathy, while high levels of autonomy contribute to satisfaction. Spreitzer (2008) suggests that there is a strong relationship between the meaning dimension and job satisfaction, and to a lesser extent with the competence dimension, and satisfaction is related with the impact dimension by increasing involvement with the work and enabling individuals to perceive their contribution to the results (Bordin et al., 2006).

Hypothesis $\mathrm{H}_{6 \mathrm{a}}$, which foresees a significant and positive relationship between an enabling PMS mediated by psychological empowerment and task performance, was supported ( $p$-value $<0.01$ ). This indicates that by providing employees with an enabling PMS that associates the availability of information at all levels of a company with the possibility of actively handling it, understanding its logic, and using it as a support tool to meet their demands, and that favors learning, can make them view their work environment positively. They will thus have the elements needed to execute their work adequately and will experience psychological empowerment. Perceiving intrinsic motivation in their work, employees will act more favorably in relation to the demands of their work context in order to obtain better results. Although Liden et al. (2000), Seibert et al. (2004), and Wang and Lee (2009) did not investigate SCG or PMS, their findings relate to characteristic elements of these systems, with indication that such elements could occur in a PMS, which is an aspect that is corroborated by this study and which jointly reinforces the elements noted in these studies.

Hypothesis $\mathrm{H}_{6 \mathrm{~b}}$, which foresees a significant and positive relationship between an enabling PMS mediated by psychological empowerment and job satisfaction, was supported ( $\mathrm{p}$-value $<0.001$ ). This result suggests that in interacting with an enabling PMS employees can perceive psychological empowerment; that is, they experience that in the relationship between the individual and the work environment the competence, impact, self-determination, and meaning dimensions are present, which are susceptible to meeting the intrinsic needs of the individual and are associated with higher levels of job satisfaction. This result corroborates with the finding of Burney and Matherly (2007) that an integrated PMS offering relevant information for the work is positively associated with 
job satisfaction; however, the comprehensibility of the system, that is, its offering a wide variety of performance indicators, was not revealed as being associated with job satisfaction in the aforementioned study.

Burney and Matherly (2007) argue that providing a wide range of indicators would be involved in shaping a holistic vision of an organization's functioning in order to increase confidence in decision making. This justification is close to the conception of internal and global transparency that composes the concept of enabling PMS. However, the definition of internal transparency includes exposure to the logic behind the functioning of the processes and information in an intelligible way, which suggests that it is not enough to make a volume of information available; it needs to be in a format that the individual can understand and associate with the functioning of the system so that the perception of the relevance of this information can trigger the feeling of psychological empowerment and thus be connected with job satisfaction. This intricate relationship that leads information from a PMS to affect satisfaction may explain the evidence found in this study, given the absence of any relationship found in the study from Burney and Matherly (2007).

The results of the theoretical-empirical model, when viewed comprehensively, may indicate that even in environments with mechanistic controls, a strict focus on standardization, and documented processes, as occurs in an SSC, it is possible to stimulate psychological empowerment and obtain positive results in task performance and job satisfaction. However, this implies adjusting the PMS in order to enable an understanding of the logic behind its factors and allows the employees to relate to these systems in a way that favors learning and the use of their skills.

In their study, considered to be the first review of the literature on SSCs, Richter \& Bruhl (2017) verified that of the 83 articles identified there was no use of psychological theories to explain phenomena that occur in these organizations. In general, the studies apply economic, strategy-related, and socio-organizational theories and seek to verify the relationship between governance practices, the level of centralization, and technological dependence, on organizational performance, generally by means of different aspects of the strategic configuration of these companies (Richter \& Bruhl, 2017).

The scenario presented by the research from Richter and Bruhl (2017) denotes the difficulty in contextualizing the findings of this study. However, in studies with similar characteristics, such as that of Hechanova, Alampay, and Franco (2006), which investigated the relationship between the psychological empowerment, satisfaction, and performance at work of Asian employees from five service sectors (hotel, call center, banking, food, and airline), psychological empowerment was shown to be positively associated with performance and satisfaction. However, the employees from the call canter and airline areas reported lower levels of empowerment and satisfaction compared to the other sectors. The authors argue that structural characteristics designed to support companies' business models, such as an orientation towards productivity, following strict norms, distance between employee and client, and possibilities for customization, which are aspects that are also present in an SSC, are relevant for understanding the results. Such evidence reinforces the results of this study by indicating that approaches need to be found that can enable the occurrence of empowerment in these environments, given the positive results of this occurrence.

Spreitzer (2008) had already observed that the perception of individuals regarding the elements that compose their work environment is a determinant of their psychological empowerment. In this sense, despite the restriction inherent to an SSC environment, individuals can obtain a positive perception as long as there is stimulation for this, which the evidence of this study indicates as being possible through an enabling PMS. By showing that such relationships are possible in an SSC, it could be suggested that in environments with fluid controls the results would have an even more prominent potential.

\section{FINAL REMARKS}

The study analyzed the impacts of PMSs with enabling characteristics on task performance and job satisfaction. The results indicated that the theory of enabling controls applied to a PMS is consistent with psychological empowerment. PMSs are expressive in the organizational context due to their ability to influence the behavior of employees and obtain cooperation in order to achieve organizational objectives (Demartini, 2014). This study suggests that this is due to the perception of psychological empowerment created by configuring a PMS based on an enabling logic and thus enabling greater integration between PMS and user. 
The results of this study confirm the importance of sharing information highlighted in the management practices mentioned by Kanter (1977), which is a key element for empowerment. However, merely allowing employee access to a wide range of information may not be enough (Burney \& Matherly, 2007), given that an enabling PMS proposes the sharing of information, however with a focus on intelligibility and exposing its underlying logic, which are elements that place the user of the PMS in an active position with relation to the system. PMSs that support enabling characteristics can also be effective in influencing employee motivation and performance, as well as positively contributing to job satisfaction. Considering that the attention of managers is limited (Simons, 1992), configuring an enabling PMS could be an alternative in contexts in which the managers are particularly in demand or are constrained in their actions.

Another point that stands out is the context of this study. SSCs are characterized as work environments with detailed and established routines with a high volume of demand (Bergeron, 2003). These characteristics are shown to be attributable to mechanistic organizations, but the results enable it to be suggested that even in less organic environments, implementing an enabling PMS can work as an element that is able to bypass the adverse effects of the context and stimulate psychological empowerment, producing attitudinal results and positive behaviors. Thus, the validation of the model proposed in an SSC indicates that the paradox between simultaneously controlling and allowing flexibility can be addressed via enabling controls (Ahrens \& Chapman, 2004). Employing systems and processes that are configured using the logic of usability (Adler \& Borys, 1996) would result in controls with greater legitimacy and less prominent mechanistic characteristics.
However, the conclusions of this study require prudence since it concerns a cross-sectional study carried out in only one organization and contextual or temporal differences may lead to different results. Although the theory presents the expected direction of the relationships, cross-sectional studies can identify whether such aspects are confirmed empirically. Studies with temporal-longitudinal cross sections that evaluate the causality relationships between the variables in this study can contribute to a greater understanding of the model. In addition, operational workers that carry out administrative, accounting, and financial activities in an SSC were investigated; therefore, managers or employees that perform activities with other characteristics may present different perceptions.

It is recommended that studies on characteristics of PMSs investigate in other operational ways the relationship between enabling controls and psychological empowerment in order to broaden and consolidate the evidence on the topic, since the theory of enabling controls denotes relationships with cognitive and motivational aspects that still require empirical verifications and have the potential to show other associations between PMSs and positive organizational results. Future studies should consider possible risks of adopting the constructs, such as the possible isolated effects of certain dimensions over the results and the occurrence of a trade-off that may be hidden when using second order or one-dimensional variables, with a greater emphasis on the enabling PMS construct, which has characteristics that have barely been explored in a quantitative way in the literature. Another suggestion is that the relationships suggested in this model are analyzed using other methodological designs and statistical techniques in order to increase the validity and reliability of this evidence.

\section{REFERENCES}

Adler, P. S., \& Borys, B. (1996). Two types of bureaucracy: enabling and coercive. Administrative Science Quarterly, 41(1), 61-89.

Ahrens, T., \& Chapman, C. S. (2004). Accounting for flexibility and efficiency: a field study of management control systems in a restaurant chain. Contemporary Accounting Research, 21(2), 271-301.

Bandura, A. (1986). Social foundations of thought and action. Englewood, NJ: Prentice Hall.

Becker, J., Klein, K., \& Wetzels, M. (2012). Hierarchical latent variable models in PLS-SEM: guidelines for using reflectiveformative type models. Long Range Planning, 45(5), 359-394.

Bergeron, B. (2003). Essentials of shared services. Hoboken: Wiley.

Birnberg, J. G., Luft, J., \& Shields, M. D. (2006). Psychology theory in management accounting research. In Hopwoof, A. G., \&
Chapman, C. S. (Orgs.). Handbook of management accounting research (pp. 111-135). Amsterdam: Elsevier.

Bordin, C., Bartram, T., \& Casimir, G. (2006). The antecedents and consequences of psychological empowerment among Singaporean IT employees. Management Research News, 30(1), 34-46.

Burney, L. L., \& Matherly, M. (2007). Examining performance measurement from an integrated perspective. Journal of Information Systems, 21(2), 49-68.

Carroll, S. J., \& Schneier, C. E. (1982). Performance appraisal and review systems: the identification, measurement, and development of performance in organizations. Glenview, IL: Scott, Foresman

Chan, Y. H., Nadler, S. S., \& Hargis, M. B. (2015). Attitudinal and behavioral outcomes of employees' psychological 
empowerment: a structural equation modeling approach. Journal of Organizational Culture, Communication and Conflict, 19(1), 24-41.

Chenhall, R. H. (2003). Management control systems design within its organizational context: findings from contingencybased research and directions for the future. Accounting, Organizations and Society, 28(2), 127-168.

Chiang, C. F., \& Hsieh, T. S. (2012). The impacts of perceived organizational support and psychological empowerment on job performance: the mediating effects of organizational citizenship behavior. International Journal of Hospitality Management, 31(1), 180-190.

Conger, J. A., \& Kanungo, R. N. (1988). The empowerment process: integrating theory and practice. Academy of Management Review, 13(3), 471-482.

DeLone, W. H., \& McLean, E. R. (2003). The DeLone and McLean model of information systems success: a ten-year update. Journal of Management Information Systems, 19(4), 9-30.

Demartini, C. (2014). Performance management systems. Berlin: Springer.

Drake, A. R., Wong, J., \& Salter, S. B. (2007). Empowerment, motivation, and performance: examining the impact of feedback and incentives on nonmanagement employees. Behavioral Research in Accounting, 19(1), 71-89.

Flamholtz, E. G., Das, T. K., \& Tsui, A. S. (1985). Toward an integrative framework of organizational control. Accounting, Organizations and Society, 10(1), 35-50.

Fornell, C., \& Larcker, D. F. (1981). Structural equation models with unobservable variables and measurement error: algebra and statistics. Journal of Marketing Research, 18(3), 382-388.

Franco-Santos, M., Lucianetti, L., \& Bourne, M. (2012). Contemporary performance measurement systems: a review of their consequences and a framework for research. Management Accounting Research, 23(2), 79-119.

Hair Jr., J. F., Hult, G. T. M., Ringle, C., \& Sarstedt, M. (2016). A primer on partial least squares structural equation modeling (PLS-SEM). London: Sage Publication.

Hall, M. (2008). The effect of comprehensive performance measurement systems on role clarity, psychological empowerment and managerial performance. Accounting, Organizations and Society, 33(2), 141-163.

He, P., Murrmann, S. K., \& Perdue, R. R. (2010). An investigation of the relationships among employee empowerment, employee perceived service quality, and employee job satisfaction in a US hospitality organization. Journal of Foodservice Business Research, 13(1), 36-50.

Hechanova, M., Alampay, R. B. A., \& Franco, E. P. (2006). Psychological empowerment, job satisfaction and performance among Filipino service workers. Asian Journal of Social Psychology, 9(1), 72-78.

Holdsworth, L., \& Cartwright, S. (2003). Empowerment, stress and satisfaction: an exploratory study of a call centre. Leadership \& Organization Development Journal, 24(3), 131-140.

Ishzaka, A., \& Blakiston, R. (2012). The 18C's model for a successful long-term outsourcing arrangement. Industrial Marketing Management, 41(7), 1071-1080.
Jordan, S., \& Messner, M. (2012). Enabling control and the problem of incomplete performance indicators. Accounting, Organizations and Society, 37(8), 544-564.

Kanter, R. M. (1977). Men and women of the corporation. New York, NY: Basic Books.

Kathuria, R., \& Davis, E. B. (2001). Quality and work force management practices: the managerial performance implication. Production and Operations Management, 10(4), 460-477.

Kuntz, J., \& Roberts, A. (2014). Engagement and identification: an investigation of social and organizational predictors in an HR offshoring context. Strategic Outsourcing: An International Journal, 7(3), 253-274.

Laschinger, H. K. S., Finegan, J. E., Shamian, J., \& Wilk, P. (2004). A longitudinal analysis of the impact of workplace empowerment on work satisfaction. Journal of Organizational Behavior, 25(4), 527-545.

Laschinger, H. K. S., Finegan, J., Shamian, J., \& Wilk, P. (2001). Impact of structural and psychological empowerment on job strain in nursing work settings: expanding Kanter's model. Journal of Nursing Administration, 31(5), 260-272.

Latan, H., Ringle, C. M., \& Jabbour, C. J. C. (2016). Whistleblowing intentions among public accountants in Indonesia: testing for the moderation effects. Journal of Business Ethics (2016). Retrieved from https://doi. org/10.1007/s10551-016-3318-0.

Liden, R. C., Wayne, S. J., \& Sparrowe, R. T. (2000). An examination of the mediating role of psychological empowerment on the relations between the job, interpersonal relationships, and work outcomes. Journal of Applied Psychology, 85(3), 407-416.

Mahama, H., \& Cheng, M. M. (2013). The effect of managers' enabling perceptions on costing system use, psychological empowerment, and task performance. Behavioral Research in Accounting, 25(1), 89-114.

Marginson, D., Mcaulay, L., Roush, M., \& Van Zijl, T. (2014). Examining a positive psychological role for performance measures. Management Accounting Research, 25(1), 63-75.

Mostafa, A. M. S., \& Gould-Williams, J. S. (2014). Testing the mediation effect of person-organization fit on the relationship between high performance HR practices and employee outcomes in the Egyptian public sector. The International Journal of Human Resource Management, 25(2), 276-292.

Mundy, J. (2010). Creating dynamic tensions through a balanced use of management control systems. Accounting, Organizations and Society, 35(5), 499-523.

Palomino, M. N., \& Frezatti, F. (2016). Role conflict, role ambiguity and job satisfaction: Perceptions of the Brazilian controllers. Revista de Administração, 51(1), 165-181.

Peng, D. X., \& Lai, F. (2012). Using partial least squares in operations management research: A practical guideline and summary of past research. Journal of Operations Management, 30(6), 467-480.

Richter, C. P., \& Bruhl, R. (2017). Shared service center research: A review of the past, present, and future. European Management Journal, 35(1), 26-38.

Ringle, C. M., Sarstedt, M., \& Straub, D. (2012). A critical look at the use of PLS-SEM. MIS Quarterly, 36(1), III-XIV. 
Schulz, V., \& Brenner, W. (2010). Characteristics of shared service centers. Transforming Government: People, Process and Policy, 4(3), 210-219.

Seibert, S. E., Silver, S. R., \& Randolph, W. A. (2004). Taking empowerment to the next level: a multiple-level model of empowerment, performance, and satisfaction. Academy of Management Journal, 47(3), 332-349.

Seibert, S. E., Wang, G., \& Courtright, S. H. (2011). Antecedents and consequences of psychological and team empowerment in organizations: a meta-analytic review. Journal of Applied Psychology, 96(5), 981-1003.

Simons, R. (1992). The role of management control systems in creating competitive advantage: new perspectives. In Emmanuel, C., Otley, D., \& Merchant, K. (Eds.). The role of management control systems in creating competitive advantage: new perspectives (pp. 622-645). New York, NY: Springer.

Spreitzer, G. M. (1995). Psychological empowerment in the workplace: dimensions, measurement, and validation. Academy of Management Journal, 38(5), 1442-1465.

Spreitzer, G. M. (2008). Taking stock: a review of more than twenty years of research on empowerment at work. In Cooper, C., \& Barlin J. (Orgs.). Handbook of organizational behavior (pp. 54-73). Thousand Oaks, CA: Sage Publications.

Spreitzer, G. M., Kizilos, M. A., \& Nason, S. W. (1997). A dimensional analysis of the relationship between psychological empowerment and effectiveness satisfaction, and strain. Journal of Management, 23(5), 679-704.

Tarrant, T., \& Sabo, C. E. (2010). Role conflict, role ambiguity, and job satisfaction in nurse executives. Nursing Administration Quarterly, 34(1), 72-82.

Thomas, K. W., \& Velthouse, B. A. (1990). Cognitive elements of empowerment: an "interpretive" model of intrinsic task motivation. Academy of Management Review, 15(4), 666-681.

Van Der Hauwaert, E., \& Bruggeman, W. (2015). The effect of monetary rewards on autonomous motivation in an enabling performance measurement context. Corporate Ownership \& Control, 12(3), 341-356.

Wang, G., \& Lee, P. D. (2009). Psychological empowerment and job satisfaction: an analysis of interactive effects. Group \& Organization Management, 34(3), 271-296.

Widener, S. K. (2014). Researching the human side of management control: using survey-based methods. In Otley, D. T., \& Soin, K. (Eds.). Management control and uncertainty (pp. 69-82). Basingstoke: Palgrave Macmillan.

Wouters, M., \& Wilderom, C. (2008). Developing performancemeasurement systems as enabling formalization: a longitudinal field study of a logistics department. Accounting, Organizations and Society, 33(4), 488-516.

Wouters, M., \& Roijmans, D. (2011). Using prototypes to induce experimentation and knowledge integration in the development of enabling accounting information. Contemporary Accounting Research, 28(2), 708-736.

Yuliansyah, Y., \& Khan, A. A. (2015). Strategic performance measurement system: a service sector and lower level employees empirical investigation. Corporate Ownership \& Control, 12(3), 304-316. 